\title{
New Model for the Estimation of Solar Radiation on Façades in Urban Environments
}

\author{
A. Márquez-García, M. Varo-Martínez and R. López-Luque \\ Research Group on Physics for Renewable Energy and Resources \\ University of Cordoba, \\ Campus of Rabanales, 14014 Cordoba (Spain) \\ Phone/Fax number:+0034957 212068,e-mail: z22magaa@uco.es, fa2vamam@uco.es, fa1lolur@uco.es
}

\begin{abstract}
.
This paper presents a new solar irradiance model for the estimation of the solar radiation on façades of buildings in urban environments. A model and a computer tool, using Visual Basic Application of Excel, have been developed to analyse in detail the radiation on façades. It can be used to determine, in a very intuitive, easy and fast way, using solar radiation contour maps, the best areas for the installation of photovoltaic systems. Finally, using the data obtained by the solar irradiance model for an application example, the electricity production of a photovoltaic system located at the selected façade is analyzed and discussed.
\end{abstract}

\section{Key words}

Solar Irradiance Model, Building Façades, Urban Environments, Sky View Factor, Shading.

\section{Introduction}

In recent years many studies about the generation of electricity using photovoltaic systems in urban environments have been made. For that purpose, a detailed knowledge of the irradiance values in cities is required [1] in order to make reliable simulations of the amount of the electricity which could be produced [2]. In this context, the façades of buildings are important elements where a great solar radiation is available. Thus, solar radiation contour maps on façades could be very useful to identify, in an intuitive and fast way, the best areas to install photovoltaic systems, to size them and to simulate the amount of electrical energy produced by them [3].

However, the estimation of solar irradiance on building façades in cities is complex, since it is necessary to know the shadows produced by the surrounding buildings and its behaviour along the day [4]. Furthermore, the diffuse and reflected components [5] of the irradiance depend on the height of the point on the façade considered, what makes even more difficult to obtain reliable estimations of the irradiance values received on facades of building in urban environments.
This paper presents a new solar irradiance model to estimate the direct, diffuse and reflected components in urban environments. For that purpose, a new parameter, called Sky View Factor (SVF), which takes into account the height of the point of the façade considered and, consequently, provides more precise results for the diffuse and reflected components in complex urban environments, is also defined. Furthermore, a computer tool based on this model has been programmed, using Visual Basic of Excel, in order to reduce its calculation time when the irradiance model is applied to complex urban environments with lots of possible interactions between buildings to take into account. The model and the computer tool are applied to an example and the results obtained are used for the creation of a solar radiation contour map of the selected façade. Finally, as an application example, an electric production simulation for a photovoltaic system located at a selected point located on the façade is shown.

\section{Solar Irradiance Model for the Analysis of Radiation on Façades in Urban Environments}

This model is based on the fact that the global irradiance received on a specific point is composed of three terms [6]: direct, diffuse and reflected irradiance. When the studied point is located on a place without elements around, such as buildings or trees, the effect of the shadows during the day on the irradiance and, consequently, on the solar radiation, can be rejected. However, in complex urban environments, where the presence of buildings is very common, the shadows produced on the studied point must be analysed in detail. In addition, the study of the global irradiance on façades of buildings requires further considerations, since the relative position of the studied point on the specific façade will determine the amount of diffuse and reflected irradiance received. Accordingly, a new equation for the estimation of the irradiance on façades in urban environments has been developed (Eq.1).

$$
I=\frac{\vec{n} \cdot \vec{s}}{\vec{k} \cdot \vec{s}} I b+S V F \cdot I d+(1-S V F) \cdot \rho^{\prime} \cdot(I b+I d)
$$


where $\vec{n}$ is the normal vector of the external face of the façade, $\vec{s}$ the Solar vector, $\vec{k}$ the normal vector of the tangent plane of the studied place, $\rho^{\prime}$ the Albedo, $I b$ and $I d$ the Direct and Diffuse irradiance on horizontal surface, respectively, and $S V F$ the Sky View Factor.

The direct irradiance, first term in Eq.1, is the one that comes straight from the sun, having the greatest influence on the global irradiance. When the studied point is shaded, this term takes the value zero. Fig. 1 shows sets out the different conditions for shading on building façades in complex urban environments: when a neighbouring building is producing shadow on that point (condition 1), when the sun is located behind the selected façade (condition 2) and during the night (condition 3).

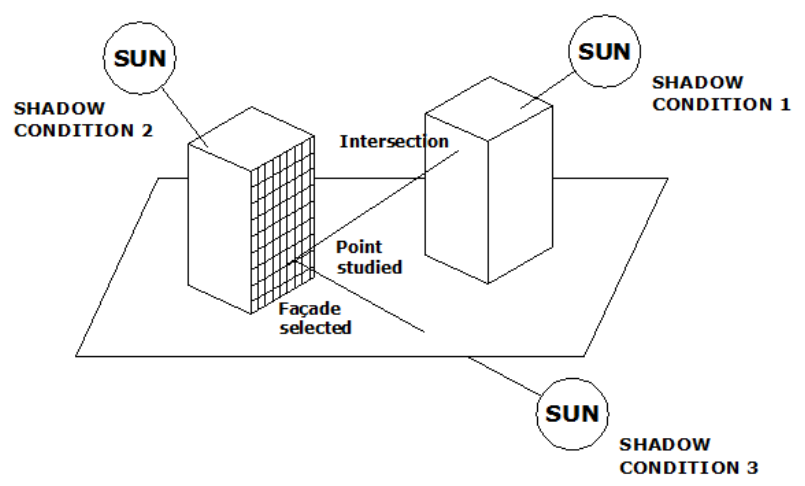

Fig. 1. Shadow conditions for building façades in urban environments

The second and third terms of Eq.1 are, respectively, the diffuse and the reflected irradiance. Both of them keep a direct relation with the dimensionless parameter Sky View Factor, SVF. This factor represents the portion of sky seen from the studied point of the selected façade. It ranges from 0 , when a $0 \%$ of the sky vault is seen from the point, to 0.5 , when there is no obstacle in the horizon. Thus, in urban environments, the SKF will be minimum for the lowest points of the building façades and maximum for the highest ones. Accordingly, the higher the SVF is, the more diffuse irradiance will be received on the point of study.

On the other hand, the complementary value of SVF, represents the obstacles, buildings and floor seen from the studied point. The lower the study point is located on the façade, the more obstacles and floor will be seen from it and, consequently, the more reflected irradiance will receive.

Therefore, this new model for solar irradiance on façades has the advantage of estimating the diffuse and the reflected irradiance related to the portion of sky vault and obstacles seen from the studied point, by means of the SVF, getting a more realistic simulation for the global irradiance.

\section{B. SOFTWARE DEVELOPED}

Eq.1. estimates the irradiance received on a specific point of the façade of a building due to the interactions with its neighbouring buildings. In complex urban environments, there could be a great amount of possible interactions between the buildings that may be considered for the analysis of shading on façades. To automate the calculation for different points of the façade and several buildings, a computing code has been developed, creating some functions and subroutines in Visual Basic environment of Excel.

\section{Shadow Subroutine}

This function determines whether a point of façade is shaded or not. For that, it uses Julian day, latitude, selected façade, solar time and two parameters, which indicate a point on the chosen façade. Specifically, each façade is represented by a local reference system with axis $\rho$ and $\mu$. Their values belong to the interval ( $0-1)$, with a step of 0.1 . It implies that 121 points of each façade are studied. The output of the Shadow Subroutine for each point of the façade with will be 0 if the point is shaded and 1 if not. For calculating the state of the point, first of all, it is necessary to establish its Cartesian coordinates inside the global reference system of the urban environment. After that, the sun position will be determined for the Julian day, latitude and solar time selected. At this point, the subroutine will calculate the intersections between the straight line going from the sun to the point of study (sunfaçade point) and the planes that contain the neighbouring façades (Fig.2). To calculate the intersection point, a three equations system must be solved, Eq.2, and the values for a, b and c, (Fig.2) will be determined. The studied point will be shaded if "a" is greater than cero or " $b$ " and "c" belong to the interval (0-1).

$$
\left(\begin{array}{c}
X_{0} \\
Y_{0} \\
Z_{0}
\end{array}\right)+a\left(\begin{array}{c}
S_{x} \\
S_{y} \\
S_{z}
\end{array}\right)=\left(\begin{array}{c}
X_{1} \\
Y_{1} \\
Z_{1}
\end{array}\right)+b\left(\begin{array}{l}
V_{12 x} \\
V_{12 y} \\
V_{12 z}
\end{array}\right)+c\left(\begin{array}{c}
V_{23 x} \\
V_{23 y} \\
V_{23 z}
\end{array}\right)
$$

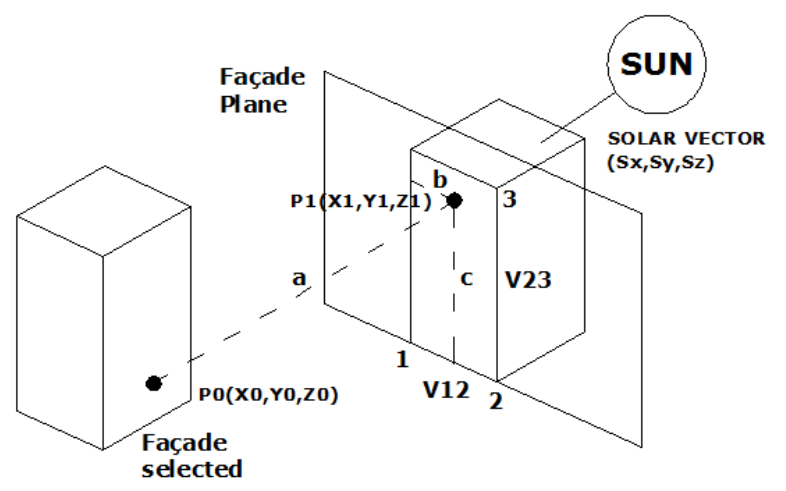

Fig. 2. Representation of the geometric intersection of solar rays and the buildings in urban environments

If the function checks that one intersection point is inside a façade of an adjacent building, it will stop and its value will be 0 , condition 1 in Fig. 1 . Its result will be also 0 , if 
the selected solar time is before sunrise or after sunset, condition 3 in Fig.1. The last condition for shading is that the normal vector of the external face of the façade cannot form an obtuse angle with the solar vector, condition 2 in Fig.1.

If none of these conditions happens, the output value for the Shadow Function will be 1 and the studied point will be lighted (Eq. 3)

$$
\begin{aligned}
I= & \text { Shadow Subroutine } \cdot \frac{\vec{n} \cdot \vec{s}}{\vec{k} \cdot \vec{s}} I b+S V F \cdot I d+ \\
& +(1-S V F) \cdot \rho^{\prime} \cdot(I b+I d)
\end{aligned}
$$

\section{Sky View Factor Subroutine}

In a completely shaded façade, the different points do not have the same level of irradiance since those points with a greater elevation over the ground see a bigger part of the celestial surface than the points with a lower elevation, which see more obstacles. As a consequence, the highest points receive more diffuse irradiance while the lowest ones received more reflected irradiance from the neighbouring façades and the floor. Due to the fact that the diffuse component exerts a greater influence on the global irradiance than the reflected one, the global irradiance will be higher on the highest points of the façade. To simulate this phenomenon, the Sky View Factor (SVF) Subroutine has been created.

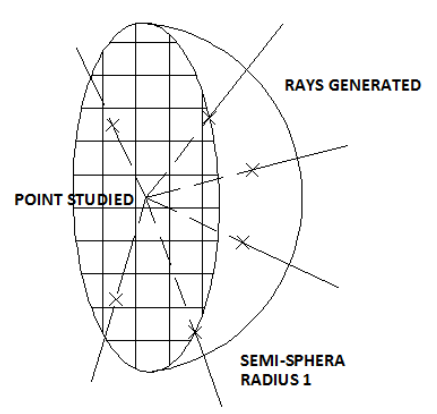

Fig.3. Generation of the rays on the selected point for the estimation of the SVF

This subroutine generates 1012 rays in different directions (Fig.3), for each one of the 121 points of the selected façade. Afterwards, it studies for each ray if it intersects with the ground or with an adjacent building, or if it has a celestial vault direction. It counts the amount of rays with sky vault direction and calculates the Sky View Factor as the quotient between it and the total of rays generated. This value and its complementary are used for estimating in a more realistic way, the diffuse and reflected component, being constant along the time (Eq. 3).

\section{Irradiance Subroutine}

The Irradiance Subroutine, based on Eq. 3, is created with the aim of estimating the irradiance $\left(\mathrm{W} / \mathrm{m}^{2}\right)$ on each point of the selected façade and for a specific solar time. The data input of this function is the latitude, the Julian day, the solar time, the parameters $\rho$ and $\mu$ of the local reference system of the façade, the selected façade, the global radiation on an horizontal surface for the specific month and the albedo.

\section{Daily Solar Radiation Subroutine}

The daily solar radiation function estimates, for each particular point of the selected façade, the accumulated energy $\left(\mathrm{kWh} / \mathrm{m}^{2}\right)$ for a particular day of the year. This subroutine uses the Irradiance Subroutine output, calculating its value each 6 minutes along the 24 hours of a day and multiplying the value obtained for 0.1 hour, getting the energy for that interval. Afterwards, this function adds the values of all intervals, in order to obtain the energy for a whole day.

\section{Solar Radiation Contour Maps on Façades. Stuttgart- Mitte}

Using the software presented, which implements the new solar radiation model for façades in urban environments, the creation of solar radiation contour maps is immediate. In this paper, a case held in the city of Stuttgart (Germany) with latitude $48.77^{\circ} \mathrm{N}$ and longitude $9.18^{\circ} \mathrm{E}$ is carried out. This city has been selected since it lies to the south of the country, where the values of global radiation on horizontal surface are greater.

In Fig.4, a model of the place of study is shown. The façade chosen belongs to the Baden Württembergische Bank building and it is located in the city centre (Stuttgart-Mitte), where the office buildings reach heights between 25 and 40 meters.

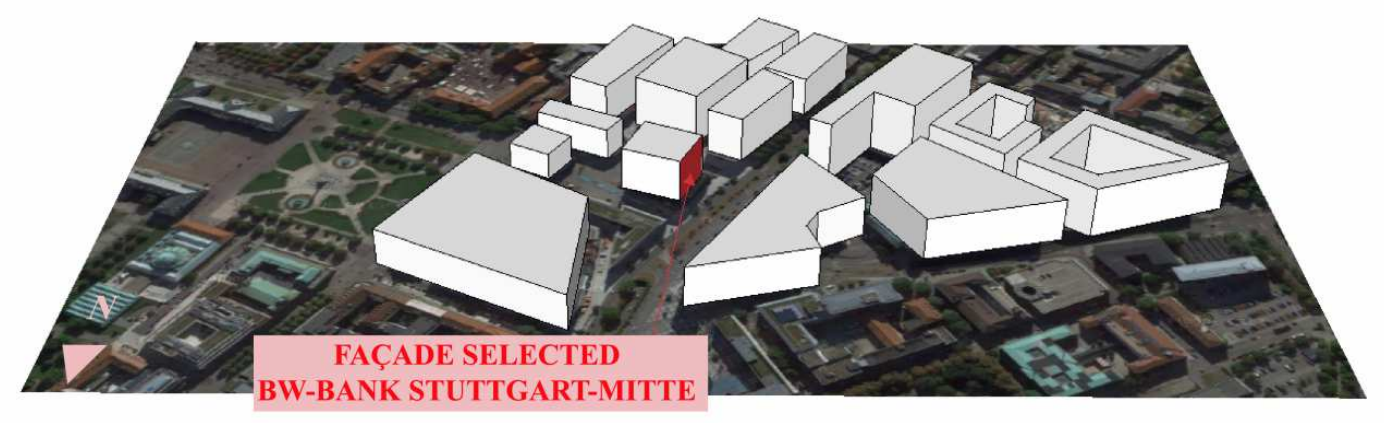

Fig. 4. Façade selected (BW-Bank Building, Stuttgart-Mitte) 


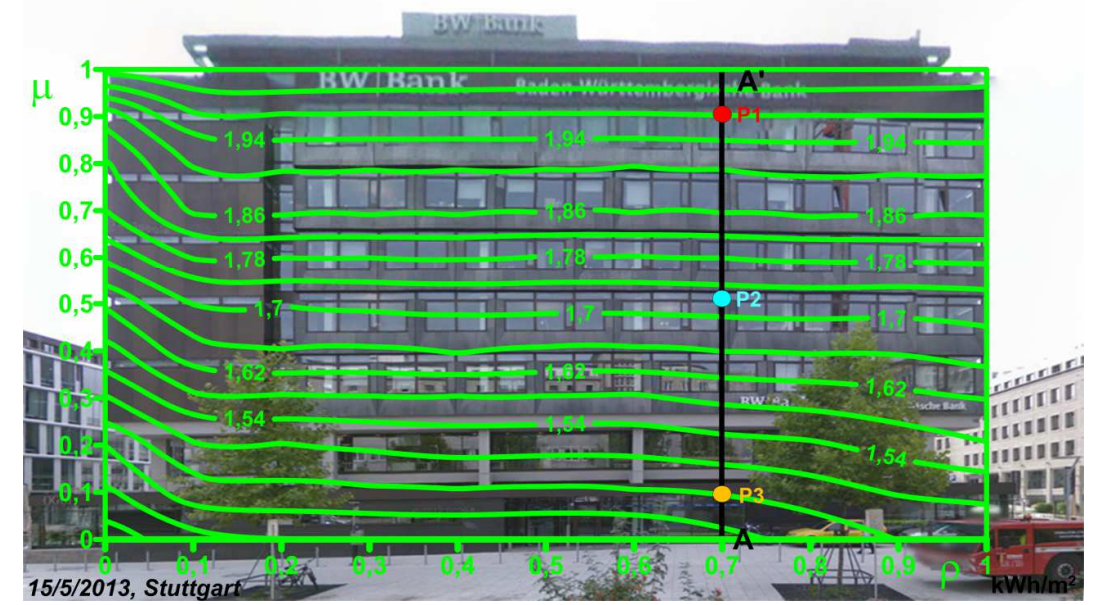

Fig. 5: Solar radiation contour map for May 15th on BW-Bank façade, Stuttgart-Mitte (Germany)

Fig. 5 shows the solar radiation contour map for May $15^{\text {th }}$, on the BW Bank building façade, created from the data generated by the irradiance model proposed. This map is very useful for choosing the area with the greatest solar radiation available. As it can be seen in Fig.5, the right side of the façade presents fewer radiation losses due to the shadows of the neighbouring buildings. On the other hand, the left side has less radiation, not being an optimal area for the installation of photovoltaic panels.

The contour map can also show, in an intuitive way, how the vertical gradient on the facade is. On all the façade the gradient is constant; however, the value of the gradient is greater on the left, since the distance between the contour lines is lower.

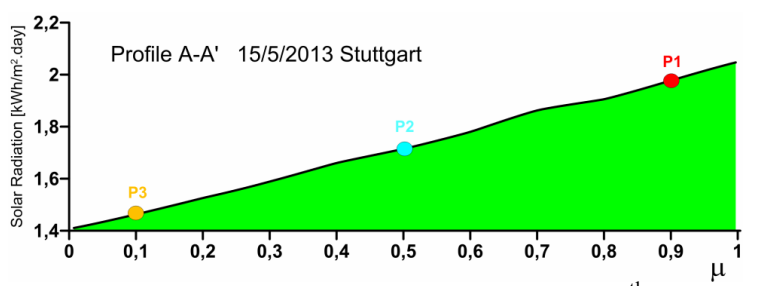

Fig. 6: Profile A-A' BW-Bank façade for May $15^{\text {th }}$. StuttgartMitte (Germany)

\section{Estimation of the Electricity Production Based on the Solar Radiation Contour Maps}

Thus, from a solar radiation contour map on a façade it is possible to identify easily and fast the most suitable area to install a photovoltaic system. However, the small investor needs accurate values of solar radiation for estimating the return of the project. The computer toolbox presented shows very accurate values for the radiation on the different points of the façade. Therefore, these data can be used to simulate the electric production generated by a grid-connected or a standalone system, being able to quantify the income.

Fig. 7 shows, for the points $\mathrm{P} 1(0.7 ; 0.9), \mathrm{P} 2(0.7 ; 0.5)$ and $\mathrm{P} 3(0.7 ; 0.2)$, located on the same vertical, the daily radiation values for the $15^{\text {th }}$ of each month. The available energy differences between each point are greater in May, June and July, the months in which the global radiation on horizontal surface is also higher. On the other hand, during the winter months, December, January and February, the radiation differences between the points are minimal. This indicates that the use of common solar radiation models has more deviations from the real values in the months in which the electric production is higher.

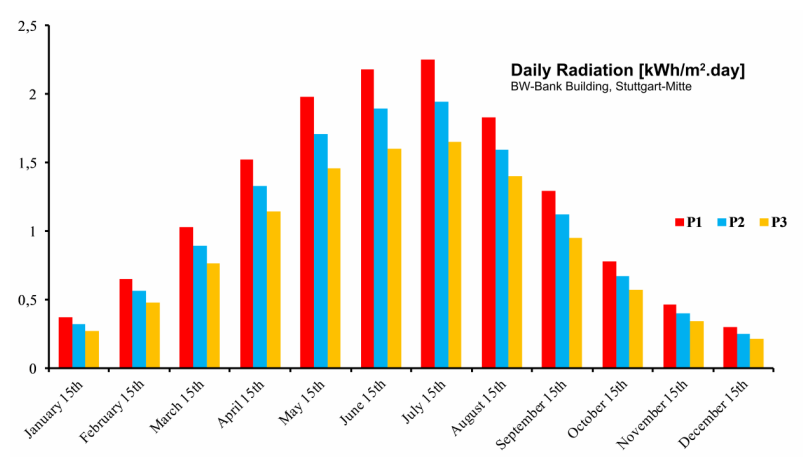

Fig. 7: Daily radiation available on 3 points on BW-Bank façade (Stuttgart-Mitte, Germany)

Table 2 shows the annual energy in $\mathrm{kWh}$ injected into the grid for a photovoltaic installation connected to the grid located at point 1 (fig 5). The installation is made up by 4 photovoltaic panels installed in parallel, each with a nominal power of $140 \mathrm{Wp}$, occupying a total area of 5.7 $\mathrm{m}^{2}$. The modules are connected to an inverter with a nominal power of $0.5 \mathrm{~kW}$.

For the simulation the software PVSYST.5 has been used, with the solar radiation data obtained on the point 1 (Fig.7) using the program created in Visual Basic, that implements the new solar irradiance model described in this article. This provides more reliable results of the total energy injected into the grid. Figure 8 shows graphically the normalized production per $\mathrm{kWp}$ installed for the case studied. Losses due to the performance of the solar panels and the inverter are also shown for each month of the year. 
Table 2. Balances and main results for point P1 on BW-Bank façade. Stuttgart-Mitte.

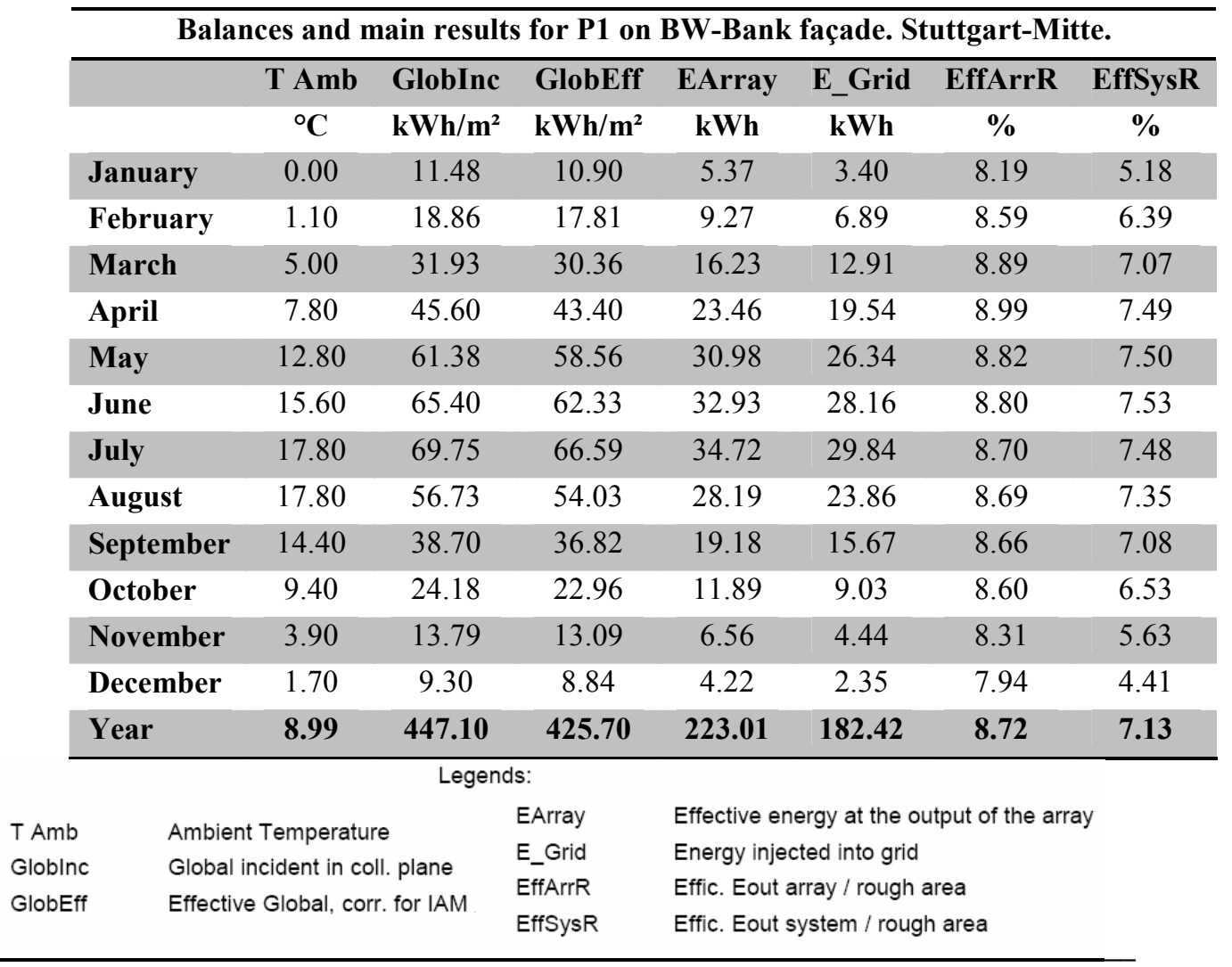

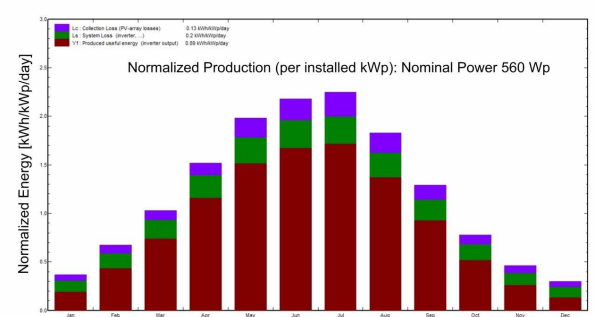

Fig. 8. Normalized production for the PV System on the point 1. BW-Bank. Stuttgart-Mitte

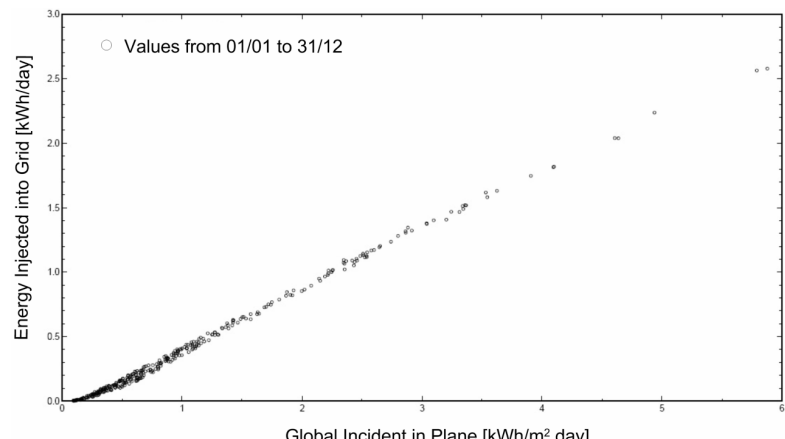

Figure 9: Global incident radiation and energy injected into the grid for each day

The representation of incident solar radiation on the photovoltaic panels and the final energy injected into the grid allows seeing easily that there is a linear relationship between the two magnitudes, and consequently, also of the losses due to the collecting system and the inverter. In Figure 9 these two variables are plotted for each day of the year. With the data obtained through this analysis, a linear regression could be performed, which would easily allow to know the final available energy from the solar radiation data. This equation would belong only to the façade studied in this case and would provide useful results of the final available energy directly from the solar radiation contour map.

\section{Discussion and Conclusions}

A new solar model to calculate the solar radiation on façades in complex urban environments has been presented in this paper. In this model, the diffuse and reflected irradiance are estimated from the portion of sky seen from each point of study on the façade. For this, a parameter called SVF, which represents the percentage of celestial vault seen from the point of study, has been created. This factor has been developed for the case of vertical façades but could be also used for sloping surfaces, such as roofs. From the irradiance values the radiation over a specific period of time could be estimated. Based on this model, a computer software tool in Visual Basic for Excel has been developed to estimate the values of solar radiation on façades. From these results, it is possible to generate solar radiation contour maps on façades that help to identify fast and easily the most suitable areas for the installation of photovoltaic panels. According to this model, the solar radiation received in the façade of the BW-Bank in the city of Stuttgart (Germany) has been estimated and a simulation of the possible electrical production in a photovoltaic 
system located at a specific point of this façade has been made using PVSYST.5 software. The accuracy of the solar radiation data obtained by the solar model presented allows better estimations of the amount of electricity injected into the grid, so it can be used to improve the estimation of the economic evaluation and the return of the investment

\section{References}

[1] M. Drif, P.J. Perez, J. Aguilera, J.D. Aguilar, A new estimation method of irradiance on a partially shaded PV generator in grid-connected photovoltaic systems, Renewable Energy 33 (2008) 2048-2056
[2] Maria La Gennusa, Giovanni Lascari, Gianfranco Rizzo, Gianluca Scaccianoce, Giancarlo Sorrentino, A model for predicting the potential diffusion of solar energy systems in complex urban environments, Energy Policy, 39 (2011) 53355343

[3] J. Mardaljevic, M. Rylatt, Irradiation mapping of complex urban environments: an image-based approach, Energy and Buildings 35 (2003) 27-35

[4] Salazar Trujillo, Jorge, Solar Performance and Shadow Behaviour in buildings, Building and Environment, Vol. 33, Nos 2-3, pp. 117-130, 1998

[5] Manuel Collares-Pereira and Ari Rabl, The Average distribution of solar radiation correlations between diffuse and hemispherical and between daily and hourly insolation values, Solar Energy 1979 Vol. 22, pp. 155-164

[6] Manuel Collares-Pereira and Ari Rabl, The Average distribution of solar radiation correlations between diffuse and hemispherical and between daily and hourly insolation values, Solar Energy 1979 Vol. 22, pp. 155-164 